\title{
Teaching Application Problems of Religious Culture and Moral Knowledge Pre-service Teachers (Case of TRNC)
}

\author{
Dr. Mehmet Karadağ ${ }^{1 *}$ and Dr. Ümit Kalkan ${ }^{2}$ \\ 1*Milli Ĕgitim Bakanlı̆̆l, Ankara, Turkey \\ ${ }^{2}$ Sosyal Bilimler Üniversitesi, Ankara, Turkey \\ I*163mkaradag@gmail.com, 2umitkalkan@gmail.com
}

\begin{abstract}
Based on the opinions and views of the senior students of theology faculties on the Religious Culture and Moral Knowledge Practical course, which they take in the last phase of their undergraduate education, it is important in terms of religious education and practical course to determine the problems they experience. The research aims to determine the difficulties experienced by novice teachers while testing basic practices about the teaching profession. As a result, it is aimed to train successful teachers for education. The research was carried out with 30 volunteer pre-service teachers who participated in the Practical Course from the senior students of the Faculty of Theology in the 2019 year. The research data were obtained using a qualitative method consisting of five open-ended questions. The content analysis method was used in analyzing the data. According to the findings of the research, the duration adequacy of the Teaching Practical course was seen as a small problem. In addition, it was revealed that the implementation items in the Teaching Practical course instruction were found to be inadequate. It was stated that the guidance of the instructor responsible for the Teaching Practical course was not adequate. Problems such as KPSS, faculty courses, excitement, and inexperience arising from the pre-service teachers themselves were identified. The other of the results obtained in the study are the problems caused by the practice school and the practice teacher.
\end{abstract}

Keywords: Religious education, Turkish Republic of Northern Cyprus, Practical course, Pre-service teacher, Practice teacher

\section{Introduction}

The most indispensable way of building future generations and raising them to the level of contemporary civilizations is education. The most essential element which cannot be overlooked after education is teaching. Teaching is the leading profession that affects human beings, the fundamentals of society, from every aspect [1]. A teacher is a behavioural determinant and the most important factor in the education process [2]. Naturally, one of the issues that should be emphasized in terms of education systems is training teachers. Training teachers in developed countries is among the priority subjects of the sciences of education in terms of both theoretical and practical (applied) aspects. The administrators, who have the

Article history:

Received (September 10, 2021), Review Result (November 5, 2021), Accepted (December 20, 2021) 
mission of keeping up with the times and introducing all the values of social life to the new generations, have endeavoured to do everything necessary to train the pre-service teachers in a well-equipped manner to reach the target of education [3]. Teaching, which provides training for pre-service teachers in teacher training programs, consists of vocational knowledge, theory, and practical courses. In this process, pre-service teachers implement the knowledge they have gained in theoretical courses through the practical course [4].

For generations that will shape our future to receive a good education and training, first of all, the teacher must have the necessary competence. Competence means that people have the desired professional equipment, skills, and attitudes in that field to properly fulfill the duties of the relevant profession [5]. Teacher competence can be defined as a teacher having adequate knowledge, ability, and attitudes to be effective and efficient in his/her profession [6]. PISA Director Andreas Schleicher stated in an interview that teaching should be made more intellectually attractive and alluring. This is only possible by giving teachers more opportunities, making them develop new ideas and projects with their colleagues and having a good mentoring system (guiding, counselling) [7]. The teacher is the most influential factor affecting the quality of education. In this respect, teacher training has always been one of the important issues of an education system [8]. Several studies have revealed that the teaching method applied by a teacher is effective for student success. The success of countries that are successful according to international exam data such as TIMSS and PISA has been explained by the importance they attach to teacher training [9].

The name of the special and real place created for education is "school". The real environment where teaching practice takes place is the school. The pre-service teacher needs to improve himself in a real environment. Pre-service teachers see the real situation at school. For the pre-service teachers to develop their teaching skills and to understand the intricacies of teaching, they must be present at the school, which is part of life. Thus, this application provides the pre-service teacher with the opportunity to both know the profession and encounter the real world [10].

Pre-service teachers face various problems during their teaching practice. Theology Faculties are not institutions that directly train teachers. However, every situation that concerns the teaching profession, in general, is also valid for the training of religion teachers in particular. It is stated that the problems encountered in teacher training are caused by factors such as planning difficulties in the implementation process, insufficient guidance in practice, and insufficient teaching material in many (quantitative, functional, and technological) aspects [11]. The failure of pre-service teachers to achieve the targeted success due to the difficulties they experience in demonstrating and developing their professional knowledge and abilities requires paying efforts to solve these problems [12].

\section{Practical course}

After referring to the teaching profession and its competency dimension in general, it would be useful to elaborate on the subtitle of teaching religion and teaching practical courses and its problems, which constitute the main problem of our study. The teacher factor is undoubtedly an important variable in religious education and teaching as in general education [13]. The person who guides the individual in understanding moral, religious, and cultural values and adapting to his/her environment and contributes to the education and training programs is the religion course teacher [14]. For this reason, religion course teachers should inevitably be educated and general policies should be determined so that he/they can have professional competence and religious education is delivered efficiently, as in all other 
branches. It will also be useful to identify the problems related to the chosen approach and methods while educating religion course teachers. It is a known fact that higher education institutions that undertake teacher education cannot train their pre-service teachers professionally enough and therefore pre-service teachers graduate without adequate competencies. It can be stated that such an opinion prevails both in vocational education and teaching practice in raising religious teachers [10].

The teaching practice part of these problems constitutes the subject of our research. The school is the most necessary environment for the pre-service teacher. Because when the practical course is conducted only in a real environment, it gives the pre-service teacher the necessary teaching skills, experience, and the intricacies of the profession [15]. For this reason, the teaching practice process should be planned and carried out correctly. The definition of the course in the teaching practice instruction of the university where the preservice teachers participating in our study were educated is as follows:

"The practical course is a 2-hour theoretical and 6-hour practical course for pre-service teachers to learn and internalize the teaching profession by observing and applying after completing some of the theoretical courses specified in the Pedagogical Formation Curriculum." [16].

The teaching practical course completed as a result of this cooperation between the university and the practice school aims at the following qualifications for pre-service teachers:

"To be able to develop the competencies required by the teaching profession by teaching at different grades of the practice school they were sent to gain teaching experience,"

"To be able to fully learn the school education curricula of their field, to interpret the textbooks and student assessment techniques used,"

"To share and improve experiences gained during teaching practices in practice schools with friends and in-service lecturers" [16].

Teaching practical courses and similar training is very important in terms of providing integrity for teacher training programs as these practices provide the pre-service teacher with experience, goal development, preparedness, technique, and method applications related to his/her profession. It is known that pre-service teachers encounter several problems during their teaching practice. These problems can be summarized as an inadequate implementation plan, insufficiency of guidance studies, and insufficiency of teaching tools and materials. It is observed that pre-service teachers behave excitedly and timidly during their teaching practices. It can be said that the problems and troubles (apathy, lack of communication) that occurred as a result of the inadequacy of the teaching staff, the school administration, and the practice teacher could not provide a healthy process for teaching practice [17].

\section{Objective}

The study aims to make a general assessment of the problems and difficulties faced by the senior students of the Faculty of Theology of the Near East University in the Turkish Republic of Northern Cyprus. The main purpose of making this assessment is to know that teacher training is very important for our children because a well-trained teacher means a well-educated child, generation, and future. An educated individual means an educated society. After all, the main purpose of education is to aim for happy societies. It is aimed to identify the problems and difficulties faced by the candidate teacher and to take the necessary 
precautions. It is aimed to identify the problems related to the practice school, practice teacher, and university mentor. Teaching is like a relay race. The person who cannot carry the flag properly may cause the team to lose. The candidate teacher is preparing to run with the flag in his hand.

With this study, it is aimed that the candidate teacher will be an efficient, strong, and experienced educator.

In the research, results were obtained in line with the opinions of the pre-service teachers. The sub-problems of the study for this purpose were determined as follows:

(1) What problems do pre-service teachers experience during the practical course process?

(2) What are the opinions of the pre-service teachers on the duration of the practical course?

(3) What are the opinions of the pre-service teachers regarding the implementation of the applications in the coursework schedule according to the application instruction?

\section{Method}

Our study is qualitative research and case study in terms of method. "Semi-structured interview form" was used as the surveying model. Qualitative research is an approach style in social sciences that uses an inductive approach and emphasizes the participant's view using descriptive data collection techniques in natural environments. The prominent feature of case studies is the in-depth investigation of one or multiple situations (s). The interview model is the oldest way of gathering information used by researchers. Interview, which is the most distinctive feature of the qualitative case study, is the in-depth investigation of one or more cases. In other words, the factors related to a situation are investigated with a holistic approach and focus on how they affect the relevant situation and how they are affected by the relevant situation. Interviewing is perhaps the oldest known way of collecting information and obtaining data available to researchers. Interviewing is perhaps the oldest known way of collecting information and data available to researchers. Dexter defines "chat for a purpose", is a process of mutual communication and interaction in the form of a question and answer for a specified goal [18]. In this framework, the expectations of pre-service teachers about the process and the problems they experienced in the process were tried to be determined. Before the research, interviews were conducted with the participants determined based on maximum diversity and voluntarism based on the necessary permissions from the Ethics Committee.

\subsection{Participants}

The study group was chosen to suit the homogeneous sampling type. Accordingly, preservice teachers were selected only from the Near East University Faculty of Theology. In the 2018-2019 academic years, qualitative research was conducted with 30 Religious Culture and Moral Knowledge pre-service teachers using personal opinion reports within the scope of the Faculty of Theology Teaching Practical Course. The gender and citizenship distribution of the pre-service teachers participating in the study is given in [Table 1]. 
Table 1. Gender and citizenship distribution of pre-service teachers

\begin{tabular}{|c|c|c|}
\hline Variables & $\mathrm{f}$ & $\%$ \\
\hline Female & 16 & 53 \\
\hline Male & 14 & 47 \\
\hline Turkish citizen & 24 & 79 \\
\hline TRNC citizen & 6 & 21 \\
\hline Total & 30 & 100 \\
\hline
\end{tabular}

When the gender distribution of pre-service teachers who participated in the study are examined, it can be seen that 53\% ( $\mathrm{f}=16)$ are females and $46 \%(\mathrm{f}=14)$ are males. The proportions of Turkish citizens and TRNC citizen students are $79 \%$ and $21 \%$, respectively. Interviews were conducted after necessary permissions were obtained from the Ministry of National Education.

\subsection{Data collection tool}

During the data collection process of the research, the necessary literature review was conducted in the preparation of the opinion report, and an interview form consisting of eight questions was prepared by considering the purpose and sub-objectives of the research. These questions were reduced to five questions by obtaining an expert opinion and further matured. The general content of these research questions includes the problems faced by the senior students of the Near East University Faculty of Theology in the practice school within the scope of the practical course.

The pre-service teachers who were practicing in the practice school, Hala Sultan Theology College, were determined and a brief preliminary interview was conducted. After the explanation was provided, a form consisting of five questions was delivered. The forms were collected later, and there was no intervention to the participants in the process. The qualitative research process is shown in [Figure 1].

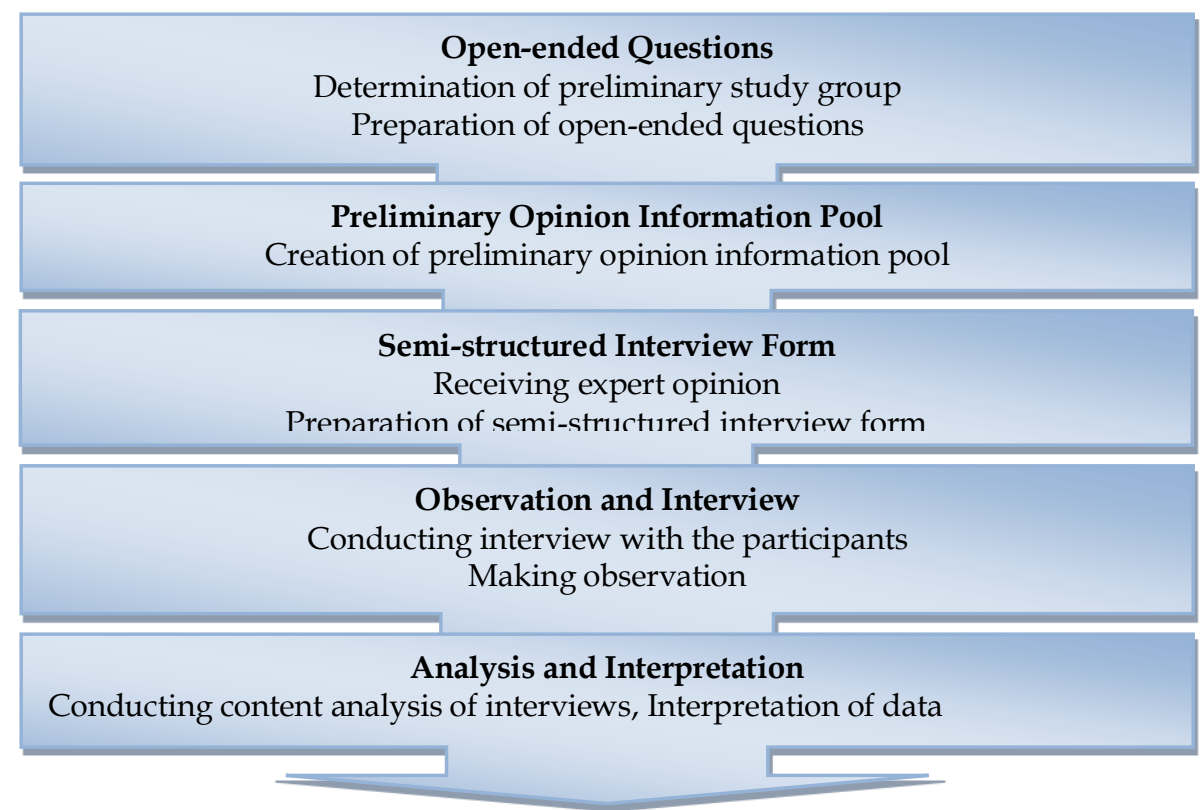

Figure 1. Qualitative research process 


\subsection{Data analysis}

A Microsoft Office program, Excel, was used to analyze the data. Data obtained from preservice teachers were interpreted according to content analysis. The purpose of content analysis is to find the concepts that will explain the data obtained and the relationships between them [18]. The data obtained from the pre-service teachers were carefully analyzed and coded. Various themes were determined in connection with coding. After the themes and codes were arranged, the findings were defined and interpreted. Main themes and sub-themes related to the research data were determined. At the same time, reference expressions related to sub-themes were tried to be given in the text. Opinions received from pre-service teachers were presented in quotation marks and italics. The opinions of the pre-service teachers were coded by giving the letters "PT" and a number indicating their order (PT1, PT2,...). While analyzing the data, it was observed that the pre-service teachers did not answer some questions or give more than one answer to certain questions. For this reason, the total number of teachers whose opinions were stated in the tables could be more or less than the number of participants. Coding was created by three researchers, who later then came together to compare the results and the analysis was finalized. As a result of the obtained data, 3 themes were created and shown in tables in the findings section.

\section{Findings}

In this section, the findings obtained from the opinions of the pre-service teachers about the process are presented as 3 themes: Practice Period, Working instructions, and Practical Problems.

The information given below shows how often pre-service teachers attending the practice school attended the courses and made observations.

Table 2. Opinions of pre-service teachers about the practical period

\begin{tabular}{|c|c|c|c|}
\hline Theme & Code & $\mathrm{f}$ & $\%$ \\
\hline \multirow{4}{*}{ 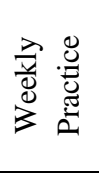 } & 2 hours & 13 & 42 \\
\hline & 3 hours & 8 & 27 \\
\hline & 4 hours & 7 & 24 \\
\hline & 6 hours & 2 & 7 \\
\hline \multirow{2}{*}{ 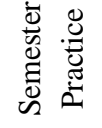 } & I think it is adequate & 17 & 57 \\
\hline & I think it is inadequate & 13 & 43 \\
\hline
\end{tabular}

According to [Table 2], pre-service teachers stated that they conducted 2 hours (36\%), 3 hours (27\%), 4 hours (30\%), and 6 hours (7\%) practice as weekly hours. This shows that this situation is not suitable for the application that should be 6 hours in the instructions [16]. The aforementioned result shows that the pre-service teachers do not act according to the instructions due to reasons such as school class hours and preparation for the Public Personnel Selection Exam (Kpss).

Indicating that he practiced 6 hours of practice in the instructions, PT5 stated his opinion as follows: "I attend 6 hours of practical courses every week. Because we have to spend 6 hours at school according to the curriculum and I want to gain some experience."

On the other hand, PT28 said: "I attend the practical course 2 hours a week. Because I also have school classes. Preparing for Kpss limits me on this issue." 
Fifty-seven percent of pre-service teachers stated that the application course is adequate for a semester whereas $43 \%$ stated that the class hours are not adequate. These data are close to each other in the opinion of pre-service teachers who find the practical course sufficient and insufficient for a semester. But the opinion that found it sufficient was more popular, albeit with a small difference. It shows that their views on both periodic and weekly implementation periods are parallel to each other.

Stating that the duration of the application was sufficient, PT29 expressed his opinion as follows: "I think it is sufficient to have the practical course for one semester because we also attend school. This situation is difficult for us."

Expressing that this period is insufficient, PT9 stated his opinion as follows: "I want to be a teacher very much. I would do anything for that. I want to gain experience under the guidance of my dear teachers. For this reason, I think it is wrong to narrow this period to one term. I think that if it lasted at least for one academic year, I could benefit more.”

Table 3. Opinions of pre-service teachers about the teaching practice teaching instructions

\begin{tabular}{|c|c|c|c|}
\hline Theme & Code & $\mathrm{f}$ & $\%$ \\
\hline \multirow{4}{*}{} & In-class observation & 30 & 100 \\
\cline { 2 - 4 } & Course coverage & 28 & 93 \\
\cline { 2 - 4 } & Preparing semester and course plans & 25 & 83 \\
\cline { 2 - 4 } & Keeping school watch and getting information & 20 & 67 \\
\cline { 2 - 4 } & In-school activity monitoring and preparation & 10 & 33 \\
\cline { 2 - 4 } & Study on assessment and evaluation & 6 & 20 \\
\cline { 2 - 4 } & Examining the class meeting minutes & 6 & 20 \\
\hline
\end{tabular}

According to [Table 3], among the practices included in the work chart of Teaching Practical Course, $100 \%$ of intra-class observation, $93 \%$ of course coverage, $83 \%$ of the semester and course plan preparation, and $67 \%$ of school watch and information-gathering was reported as completed. This case shows that a majority of pre-service teachers took part in these practices. On the other hand, 33\% was reported for intra-school activity practice, $20 \%$ was reported for measurement-evaluation-related work, and $20 \%$ was reported for examining group meeting minutes.

The PT4 answered the question on the subject as follows: "Actually, I really want to teach because the practical part of this work, i.e., the application part excites me".

On the other hand, PT19 stated the following about keeping watch: "Teaching does not mean only theoretical knowledge or teaching courses. I think I am responsible for the safety of the students while they are on a break".

PT7 provided his opinion as follows: "The practice teacher did not give much information about the assessment and evaluation and the group meeting minutes."

Table 4. Opinions of pre-service teachers about the problems encountered in the practical course process

\begin{tabular}{|c|c|c|c|}
\hline Theme & Code & $\mathrm{f}$ & $\%$ \\
\hline \multirow{4}{*}{ 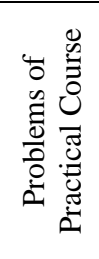 } & $\begin{array}{l}\text { Problems arising from the practice faculty member (lack of guidance and } \\
\text { communication) }\end{array}$ & 18 & 60 \\
\hline & $\begin{array}{l}\text { Problems arising from pre-service teachers (preparation for Kpss, school } \\
\text { courses, excitement, inexperience etc.) }\end{array}$ & 16 & 53 \\
\hline & $\begin{array}{l}\text { Problems arising from the practice school (transportation, document } \\
\text { tracking and planning, etc.) }\end{array}$ & 10 & 33 \\
\hline & Problems caused by the practice teacher (lack of guidance, etc.) & 3 & 10 \\
\hline
\end{tabular}


According to [Table 4], the most clearly expressed problem is associated with the practice faculty member at a $60 \%$ ratio (lack of guidance and communication). Among others, 53\% mentioned problems related to the pre-service teacher (preparation for KPSS, school classes, excitement, lack of experience, etc.). Opinions related to practice school (transportation, document tracking, and planning, etc.) are at a 33\% ratio. In addition, opinions attributing the problems to the practice teacher (lack of guidance, etc.) were determined as 10 percent.

Responding to the relevant question, PT9 said: "First of all, I thank our practice teacher. I can say that he guided us in the field of application. The practice faculty member gave information about what should be in the program, but he should have evaluated us in the course implementation".

Another candidate, PT28, said: "First of all, I think it is an exciting phase. Sharing what I know with the children makes me excited. But I think we have a lot of documents to sign".

PT23, on the other hand, expressed his opinion as follows: "The application course was very efficient. But on the one hand, our courses and exams at school restricted us from concentrating and making use of Kpss, which we need to prepare to become a teacher."

\section{Conclusion and discussion}

In our study, various difficulties of the Teaching Practical course, which is thought to be important for teacher training, in which pre-service teachers have the opportunity to apply the knowledge they have gained in undergraduate education, have been discussed. It is a fact that pre-service teachers faced many difficulties during the Teaching Practical course. Within the scope of the research, the problems such as adequacy of Teaching Practical course in terms of time, Teaching Practical course working instructions, and other problems of the Teaching Practical course (caused by the practice faculty member, caused by the pre-service teacher himself, caused by the practice school and caused by the practice teacher) were expressed.

One of the most important findings of the study is related to the duration of the Teaching Practical course. The prevailing opinion is that the duration of the courses is sufficient both weekly and per semester, but the number of pre-service teachers who think that the semester time is insufficient is also substantial. This result is not consistent with the results in the literature. However, it is worth noting that the number of candidates who think that the time is insufficient is not underestimated. This view is in line with the results of researchers in the literature who have shown that this period is insufficient and that this period should be increased [10].

For pre-service teachers to know the school and follow its functioning, to experience the classroom environment, to experience the excitement of the teaching profession they dream of, and to apply some official practices, it is necessary to implement all the application items in the Teaching Practical course working instructions. In these instructions, it was concluded that practices such as classroom observation, teaching, preparing term and course plans, keeping school shifts, and getting information, which is specified in the working instructions, were mostly performed. In similar studies in the literature, it was stated that pre-service teachers benefited from this process [19], felt like teachers with positive experiences, and liked the teaching profession [20]. During the Teaching Practical course, pre-service teachers state that lecturing in the classroom feels like a teacher and they are happy as a result of communicating with the students. For this reason, it is stated that participating in the classroom observation and teaching process is exciting. In similar studies, pre-service teachers state that the Teaching Practical course includes activities that are necessary to gain 
experience. In a similar study, it was emphasized that the practical course provided the experience to pre-service teachers [21].

However, it was concluded that the practices in the working instructions such as in-school activity monitoring and preparation, working on assessment and evaluation, and examination of class meeting minutes were not performed adequately. The reasons for leaving these practices incomplete can be explained as the practice teacher and pre-service teacher not showing enough interest in the instructions. In the literature, studies are stating that problems are arising from the implementation of the practical course working instructions [20]. Likewise, the pre-service teacher completes the work instruction incompletely because some duties and responsibilities that need to be fulfilled over time are neglected in the evaluations that should be carried out under the responsibility of the practice teacher [22].

Under the theme of practice problems in the study, the problems encountered during the practical course process with changing ratios are as follows: problems originating from the application instructor (lack of guidance and communication), problems originating from the pre-service teacher (preparation for Kpss, school courses, excitement, inexperience, etc.), problems originating from the practice school (transportation, document tracking, and planning, etc.) and problems originating from the practice teacher (lack of guidance, etc.). According to the opinions of the pre-service teachers, it was concluded that the problems originating from the practice faculty member and the pre-service teachers were predominant. In line with the same views, it was observed that the problems caused by the practice school and the practice teacher were less common.

In line with the opinions of the pre-service teachers, it was stated that the application lecturer did not sufficiently participate in the process except for the theoretical courses. This situation overlaps with some research results in the literature. It is stated that the practice faculty members could not communicate adequately and could not find solutions to the problems because they were from other departments [12]. Similarly, in the study conducted for mathematics teachers, it was concluded that the problems they encountered in undergraduate practical courses did not contribute to the teaching profession later on, so the practical courses did not contribute much to overcome the problems they encountered during teaching [23].

In the comments made by the pre-service teachers, it was stated that the lecturer attended only one course (lecture), and observed and graded based on a single lecture. In addition, it was concluded that the teaching staff gave insufficient guidance and information about the practical course. Even though the pre-service teachers are guided by the practice teachers during the application course, the lecturer of the application should be in cooperation with both the practice teachers and the pre-service teachers to make the application process more efficient. In his study, Saka (2019) states that the practice faculty member generally gives insufficient guidance at the beginning of the term and evaluates at the end of the term [24]. In addition, Şimşek, Alkan, and Erdem (2013) emphasized in their study that necessary arrangements should be made especially for communication between the practice faculty member and the practice teacher [25]. In similar studies, it is stated that the pre-service teachers stated that the lecturers could not spare enough time for them, they could not pay enough attention and they did not respond to their reports [26].

It was concluded that among the problems arising from the pre-service teacher revealed within the scope of the research, there were problems of preparation for Kpss, school classes in the school, inexperience in classroom management, and natural excitement. In general, in the studies conducted in the literature, it has been determined that there are some deficiencies due to pre-service teachers during the practical course [27][28]. In another similar study, it 
was emphasized that pre-service teachers had difficulties especially in classroom management and planning within the scope of the practical course [10]. Likewise, they stated that the most basic deficiency that pre-service teachers saw in them during the practical course was classroom management and efficient use of time. Pre-service teachers state that the main reason for their classroom management difficulties is that they are seen by students as guests rather than teachers [10]. The results of our study are in line with these data.

As stated above, it was concluded that pre-service teachers could not focus on the practical course due to serious obstacles such as Kpss and passing classes, which they care about to become teachers. In a similar study, it was concluded that pre-service teachers did not give due importance to the practical courses as the practical course was in the last year and due to their studies for Kpss [10][21]. According to another research result, the most basic problem expressed by pre-service teachers was that they could not allocate enough time for the Practical course because the application was done in the last year and there were other exams to be prepared [11].

The other two of the results obtained in the study are the problems caused by the practice school and the practice teacher. Although a small number of pre-service teachers stated these problems, it is useful to express them. In a study conducted in the literature, the problems originating from the practice school are expressed as problems caused by the school administration and the practice teacher [29]. It was stated by pre-service teachers that practice schools were remote and that they had transportation difficulties. Similar studies emphasized that due attention was not paid especially in the selection of practice schools [10][27] and that practice schools were remote [11]. Pre-service teachers state that the school administration has difficulties in paperwork, signature, and lesson planning, as well as the distance of the school.

In the study, we can assume that there is a positive counselling process between practice teachers and pre-service teachers due to the low rate of distress caused by practice teachers. Y1ldirım et al. (2019) stated that expectations of pre-service teachers about the practice teacher were met and they helped them considerably with guidance [12]. However, although the problems caused by the practice teacher in our study are low, we need to consider them as the problems experienced by pre-service teachers. In the studies conducted in the literature, it was concluded that practice teachers could not provide sufficient guidance and were far from new educational approaches [30].

\section{Recommendation}

In our research, we sought the opinions of the novice teachers about the problems of the practice lesson. As a result, we will have suggestions for both education researchers and education politicians.

\subsection{Recommendations to education politicians}

(a) Since the duration of the application course is insufficient, it is recommended that a more suitable time be determined and applied meticulously.

(b) Both the practice teacher and the university mentor should be thoroughly supervised.

(c) Since the practice course is insufficient, the practice of the course should be observed more under the supervision of the mentor and the practice teacher.

(d) Likewise, the application school should provide convenience for the candidate teacher. 


\subsection{Recommendations to authors}

(a) There are many studies for practice courses, but it is recommended to be intense especially in unsuccessful courses.

(2) Our research was prepared with a qualitative method. New research with the mixed method will contribute to the literature.

(3) We worked with candidate teachers. In similar studies, the opinions of school principals, practice teachers, mentors, and even students can be consulted.

(4) We recommend that the practical course compare the theoretical and practical dimensions.

\section{References}

[1] H. Şimşek, "Attitudes of students who continue their secondary education non-thesis master's program towards the teaching profession," Yüzüncü Y1l University Journal of Electronic Education Faculty, vol.2, no.1, pp.2- 26, (2005)

[2] O. Çepni and F. Aydın, "Problems faced by prospective geography teachers within the scope of teaching practice course and solution suggestions," TSA, vol.19, no.2, (2015)

[3] M. Karadağ, F. Altınay Aksal, Z. Altınay Gazi, and G. Dağlı, "Effect size of spiritual leadership: In the process of school culture and academic success," SAGE Open, vol.10, no.1, pp.1-14, (2020)

[4] S. Park and Oiver, "Reconceptualization of pedagogical content knowledge (PCK): PCK as a conceptual tool to understand teachers as professionals," Research in Science Education, vol.38, pp.261-284, (2008)

[5] Ü. Kalkan, F. Altınay Aksal, Z. Altınay Gazi, R. Atasoy, and G. Dağl1, "The relationship between school administrators' leadership styles, school culture, and organizational image," SAGE Open, vol.10, no.1, pp.115, (2020)

[6] F. Çınar, "The problem of teacher training in religious education," International Journal of Social Studies, vol.9, no.46, pp.607-615, (2016)

[7] A. Schleicher, "Evaluation of the Turkish education system: The main teacher," https://www.timeturk.com, (2017), https://www.timeturk.com/pisa-direktoru-andreas-schleicher-turk-egitim-sistemidegerlendirmesiaslolan-ogretmen/haber-776773

[8] E. Çetinkaya and D. Kılıç, "Examining the effectiveness level of the teaching practice course according to the opinions of school administrator's classroom teachers and pre-service teachers," Atatürk University Social Sciences Institute, vol.21, no.2, pp.561-571, (2017)

[9] PISA, "Pisa 2015 Ulusal meb.gov.tr, Http://Pisa.meb.gov.tr/Wpcontent/Uploads/2016/12/Pisa2015_ulusal_rapor1.pdf

[10] M. N. Gömleksiz, A. Ü. Kan, and Ü. Öner, "A critical approach to the teaching practice course in the perspective of effective teacher education: A qualitative review," Tarih Okulu Dergisi (TOD), vol.10, no.32, pp.927-954, (2017)

[11] F. Çaplığlu and Y. Kızılabdullah, "Opinions of practice teachers and students on the process of teaching practice at Ankara University of Theology,” Dini Araştırmalar, Din Eğitimi: Beyza Bilgin Özel Sayısı, vol.23, no.58, pp.51-78, (2020)

[12] R. G. Yıldırım, G. Özyılmaz Akamca, A. M. Ellez, S. Karabekmez, and A. N. Bulut Üner, 'Examination of pre-school teacher candidates' views on school experience and teaching practice courses," Journal of Higher Education and Science, vol.9, no.2, pp.306-316, (2019)

[13] R. Kaymakcan, "Religious culture and ethics lessons according to teachers, new trends: Pluralism d constructivism", Religious Education in Schools in Turkey, Istanbul: Values Education Center Publications, (2011) 
[14] N. Y. Aşıkoğlu, "The role of the religious education and religious teachers' qualifications (The case of Turkey)", C.Ü. Journal of the Faculty of Theology, vol.15, no.1, pp.5-13, (2011)

[15] H. -S. Lee, S. -Y. Lee, and J.-Y. Shin, "An analysis on the satisfaction and perception of performance outcomes of the university information disclosure system," Asia-Pacific Journal of Educational Management Research, vol.5, no.3, pp.47-54, (2020)

[16] YDÜ, Near East University Faculty of Theology Pedagogical Formation Teaching Practice Handbook, Lefkoşa, (2018)

[17] İ. S1lay and T. Gök, "A study on the problems that teachers' candidates encounter in practice schools and the suggestions prepared to solve these problems," presented at the XIII. National Educational Sciences Congress, Malatya, (2004)

[18] A. Yıldırım and H. Şimşek, Qualitative Research Methods in the Social Sciences. Ankara: Seçkin Publishing, (2016)

[19] E. Aslanargun, A. Kılı̧, and F. Acar, 'Guidance levels of practice teachers to teacher candidates', Electronic Journal of Social Sciences, vol.11, no.39, pp.1-21, (2012)

[20] A. Eraslan, 'Faculty-school cooperation program: Opinions of pre-service mathematics teachers on the school practice course," Hacettepe Faculty University Journal of Education, vol.34, pp.95-105, (2008)

[21] K. Y1lmaz and İ. Kab, "Opinions and evaluations of social studies teacher candidates on "school experience" and "teaching practice" courses," International Journal of Social Sciences, vol.1, pp.197-215, (2013)

[22] A. Sarıçoban, "School education and management education courses," Gazi Faculty of education Department, vol.28, no.3, pp.31-55, (2008)

[23] H. B. Yanık, O. Bağdat, Ö. Gelici, and M. Taştepe, "Complaints of middle school students on the island," Mustafa Kemal Social Sciences Institute, vol.13, no.36, pp.130-152, (2016)

[24] M. Saka, "Education and training students in the field of science and education," Elementary Education Online, vol.18, no.1, pp.127-148, (2019)

[25] S. Şimşek, V. Alkan, and A. R. Erdem, 'Nothing to work within orderly management," Pamukkale University Faculty of Department of Education, vol.34, pp.63-73, (2013)

[26] H. Özmen, 'Opinion of pre-service teachers about school experience," Ondokuz Mayis University Faculty of Department of Education, vol.25, pp.25-37, (2008)

[27] Ö. Ö. Dursun and A. Kuzu, 'Opinions of pre-service teachers and instructors about the problems experienced in the teaching practice course," Selçuk University Faculty of Department of Education, vol.25, pp.159-178, (2008)

[28] M. YIlmaz and H. Özçakmak, 'Evaluation of pre-service teachers' teaching practice courses," Bartın University Faculty of Department of Education, vol.4, no.1, pp.127-136, (2015)

[29] F. Şaşmaz-Ören, Ö. S. Sevinç, and E. Erdoğmuş, 'Evaluation of teacher candidates' towards school experience lessons," Educational Management in Theory and Practice, vol.58, pp.217-246, (2009)

[30] B. Y. Haciibrahimoğlu, 'Mental images of pre-school teacher candidates regarding the concept of "practice teacher”, Turkish Online Journal of Qualitative Inquiry (TOJQI), vol.7, no.3, pp.245-278, (2016) 